\title{
O SUPERGRUPO ESPINHAÇO EM MINAS GERAIS E BAHIA: CORRELAÇÕES ESTRATIGRÁFICAS, CONGLOMERADOS DIAMANTÍFEROS E EVOLUÇÃO GEODINÂMICA
}

\author{
ALEXANDRE UHLEIN ${ }^{1} \&$ MARIO LUIZ DE SÁ CARNEIRO CHAVES ${ }^{2}$
}

\begin{abstract}
RESUMO O artigo visa apresentar uma revisão da evolução tectono-sedimentar do Supergrupo Espinhaço nos Estados de Minas Gerais e Bahia. Estudos sedimentológicos, estratigráficos e estruturais integrados permitem reconhecer a evolução de uma bacia rifte intracratônica, desenvolvida entre 1,7-1,2 Ga. A estruturação do rifte Espinhaço nos Estados de Minas Gerais e Bahia está ligada a falhas extensionais N-S e NW-SE, com vulcanismo ácido-intermediário localizado. A sedimentação é inicialmente continental, representada por fácies de leque aluvial, fluvial e eólica, com sedimentos deltáicos e marinhos para o topo. O desenvolvimento de discordâncias e deposição de sedimentos aluviais são, provavelmente, controlados pelo tectonismo extensional. Durante fases de estabilidade tectônica, a deposição foi controlada por variações do nível dos mares. A evolução sedimentológica permite reconhecer fases sin-rifte e pós-rifte, com prováveis subsidências do tipo mecânica e termal. Conglomerados diamantíferos de diferentes idades são caracterizados e comparados, na Formaçĩo Sopa-Brumadinho (1,7 Ga) e na Formação Tombador (1,4-1,2 Ga). Intrusōes kimberlíticas/lamproíticas são sincrônicas com as fases de rifteamento e provavelmente limitadas no tempo.
\end{abstract}

Palavras-chave: Evolução tectono-sedimentar, rifte paleo-mesoproterozóico, conglomerados diamantíferos.

\begin{abstract}
THE ESPINHACO SUPERGROUP IN MINAS GERAIS AND BAHIA: STRATIGRAPHIC CORRELATIONS, DIAMOND. BEARING CONGLOMERATES AND GEODINAMIC EVOLUTION The aim of this paper is to present a review for the tectono-sedimentary evolution of the Espinhaço Supergroup in Minas Gerais and Bahia States. Integrated sedimentological, stratigraphical, structural datas allow to recognize a intracratonic rift basin evolution at 1,75-1,2 Ga. The built up of the Espinhaço rift in the States of Minas Gerais and Bahia took place along N-S and NW-SE extensional faults with acid-intermediate volcanism. The onset of the sedimentation is continental, represented by alluvial fan, fluvial and desertic facies with deltaic and shallow marine sediments. Development of the unconformities and deposition of alluvial sediments seems to be controlled by extensional tectonism. During tectonic stability, deposition seems to be controlled by transgression of the sea level. The sedimentologic evolution allow to recognize a syn-rift and post-rift phases, with probably mechanical and thermal subsidence. The diamond-bearing conglomerates of different ages are described in the Sopa-Brumadinho (1.7 Ga) and Tombador (1.4 - 1.2 Ga) formations. Kimberlitic/lamproitic intrusions are synchronous to the rifting phases and seems to be very limited in time.
\end{abstract}

Keywords: tectono-sedimentary evolution, Paleo-Mesoproterozoic rift, diamond-bearing conglomerates.

INTRODUÇÃO A Serra do Espinhaço envolve uma extensa faixa linear de direção norte-sul, que se inicia nas proximidades de Belo Horizonte (Minas Gerais), desenvolve-se para o norte, bordejando a leste o Cráton do São Francisco (regiões de Diamantina, Grão Mogol, Monte Azul, etc.) e adentra o Estado da Bahia, bifurcando-se em vários ramos (serras do Boqueirão e do Estreito) até a área lindeira aos Estados de Pernambuco e Piauí. Ela é constituída por rochas do Supergrupo Espinhaço que compreende, na base, metavulcânicas félsicas localizadas, superpostas por metassedimentos clásticos (quartzitos, conglomerados, metapelitos), com raras intercalações carbonáticas. A região da Chapada Diamantina aflora na região centro-oeste da Bahia e compreende uma sucessão de altiplanos de 900 a 1600 $\mathrm{m}$ de altitude, com rara beleza natural, constituída principalmente pelos metassedimentos do Supergrupo Espinhaço.

O Supergrupo Espinhaço compreende dois domínios de comportamento estrutural e geotectônico distintos: a Serra do Espinhaço, uma estrutura do tipo fold-thrust belt, e a região da Chapada Diamantina, uma sequência de cobertura do Cráton do São Francisco-Congo (Alkmim et al. 1993, 1996). A primeira, situada na Faixa Araçuaí e com prolongamento para o Corredor do Paramirim (Fig. 1), apresenta metamorfismo da fácies xisto verde, com dobras de eixo N-S, vergência para o
Cráton do São Francisco, xistosidade plano-axial e falhas inversas ou de empurrão com transporte para oeste. A região da Chapada Diamantina, pode ser subdividida em dois domínios estruturais: leste e oeste, separados pelo lineamento Barra do Mendes - João Correia. A leste, os sedimentos são subhorizontais e anquimetamórficos, enquanto a oeste, são dobrados, com deformação e metamorfismo aumentando para o Vale do Rio Paramirim.

Este artigo apresenta e correlaciona a estratigrafia do Supergrupo Espinhaço nos segmentos meridional e setentrional da Serra do Espinhaço e da região da Chapada Diamantina (Fig. 1). Além disto, procura situar, no contexto estratigráfico regional, as mineralizações diamantíferas do tipo paleoplacer que ocorrem no âmbito desta megaseqüência. Tal abordagem integrada permitiu reconhecer sua evolução geodinâmica em um contexto de rifte ensiálico Paleo-Mesoproterozóico, desenvolvido entre 1750 - $1200 \mathrm{Ma}$. Estes estudos permitiram ampliar o conhecimento sobre a bacia de sedimentação do Supergrupo Espinhaço, além de sugerir um modelo geodinâmico de evolução crustal.

O Supergrupo Espinhaço apresenta evolução bacinal que se iniciou no período Estateriano do Paleoproterozóico, há cerca de $1750 \mathrm{Ma}$ (Brito Neves et al. 1979, Brito Neves et al. 1995, 


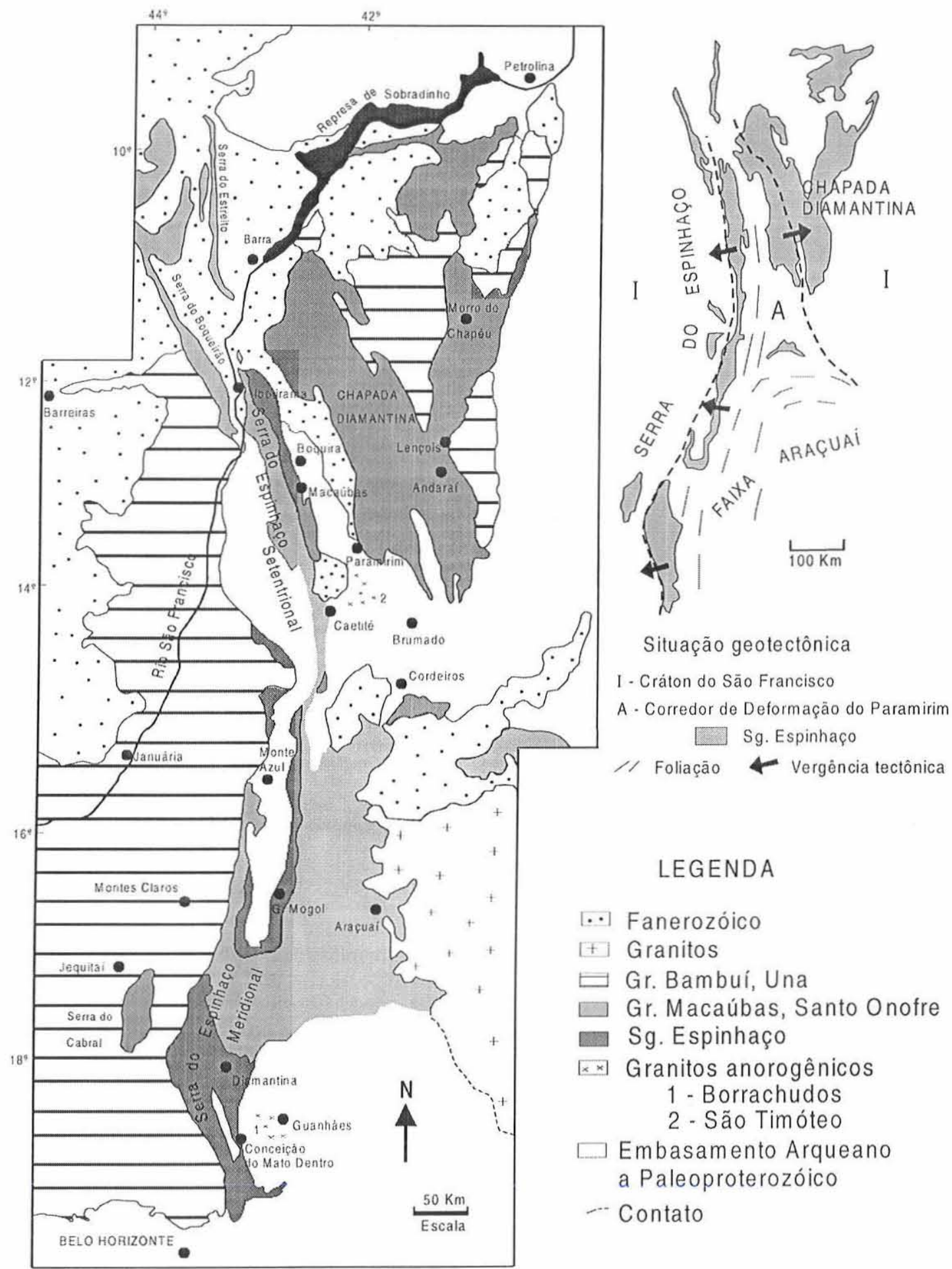

Figura I - O Supergrupo Espinhaço nos Estados de Minas Gerais e Bahia. Modificado de Schobbenhaus (1993).

Schobbenhaus 1996) e a sedimentação deve ter ocorrido até, aproximadamente, $1200 \mathrm{Ma}$ (Babinski et al. 1993). Vários ciclos sedimentares ocorreram ao longo deste tempo, com diferentes tipos de subsidência, às vezes limitados por discordâncias (Fig. 2). Uma idade mínima é indicada pelo enxame de diques máficos intrusivos no Supergrupo Espinhaço, relacionado ao intervalo 1100 a $900 \mathrm{Ma}$ (Brito Neves et al. 1979, Machado et al. 1989). A deformação orogênica, relaci- onada ao metamorfismo da fácies xisto verde, ocorreu no Ciclo Brasiliano, entre 650 e 550 Ma (Uhlein 1991, Uhlein \& Pedreira, 1989, Alkmim et al. 1993, 1996, Uhlein et al. 1995, Danderfer et al. 1993, Danderfer 2000).

ESTRATIGRAFIA DO SUPERGRUPO ESPINHAÇO EM MINAS GERAIS E BAHIA Inda \& Barbosa (1978) e Schöll \& Fogaça (1979) denominaram de Supergrupo 


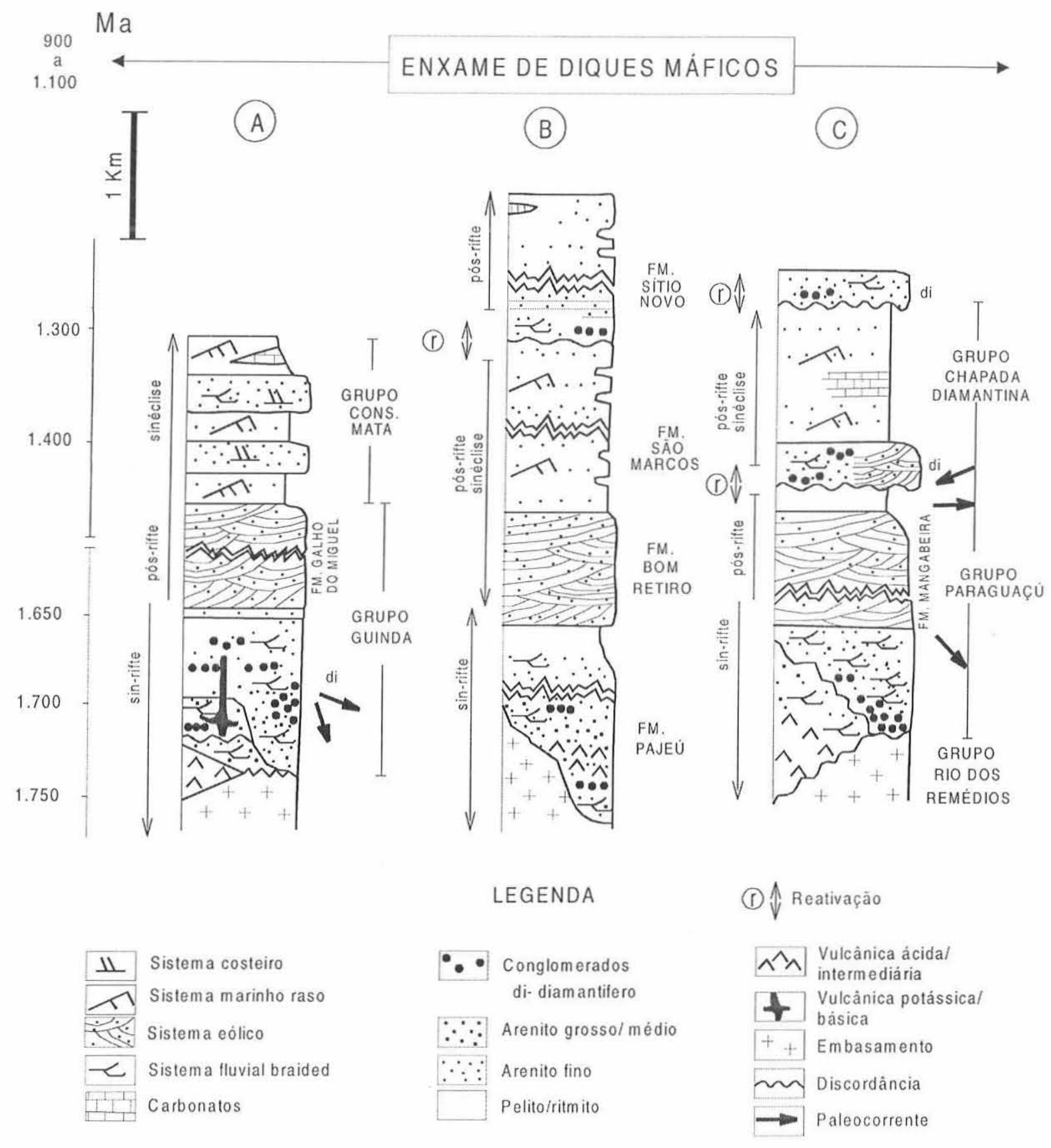

Figura 2 - Estratigrafia do Supergrupo Espinhaço na Serra homônima e na Chapada Diamantina. A - Serra do Espinhaço Meridional (Pflug 1965, 1968, Schöll \& Fogaça 1979, Uhlein 1991, Martins Neto 1993, 1998, Almeida Abreu 1993, 1995, Silva 1995).B - Serra do Espinhaço Setentrional (Schobbenhaus 1972, 1993, Danderfer 2000).C - Chapada Diamantina (Inda \& Barbosa 1978, Dominguez 1993, Pedreira 1994, 1997).

Espinhaço as seqüências predominantemente quartzíticas que suportam o relevo da Serra do Espinhaço, nos Estados de Minas Gerais e Bahia. A introdução deste termo veio substituir o termo "Série Minas" estendida à região por Pflug $(1965,1968)$ e Pflug et al. (1969) a partir da correlação das rochas aflorantes nas proximidades de Diamantina com os metassedimentos clasto-químicos do Quadrilátero Ferrífero, desde longa data conhecidos sob aquela designação. Para facilitar as descrições estratigráficas e sedimentológicas, o prefixo "meta" não será utilizado para as rochas metassedimentares de baixo grau que constituem o Supergrupo Espinhaço.
Espinhaço Meridional No setor meridional da Serra do Espinhaço, o embasamento é formado por granitos e gnaisses arqueanos, e pelo Supergrupo Rio Paraúna, uma unidade vulcano-sedimentar também arqueana, constituída por xistos verdes, formações ferríferas, micaxistos e quartzo-xistos (Schöll \& Fogaça 1979, Fogaça et al. 1984).

O Supergrupo Espinhaço neste domínio constitui uma estrutura anticlinorial de eixo norte-sul regionalmente mergulhando para norte. As unidades basais, designadas de Grupo Diamantina (Dossin et al. 1990) ou de Grupo Guinda (Almeida-Abreu 1993), ocorrem na zona centro-leste deste 
anticlinório, enquanto que as unidades superiores, designadas de Grupo Conselheiro Mata (Dossin et al. 1990) afloram no "Sinclinório de Conselheiro Mata", situado na parte oeste da serra (Fig. 2A). O Grupo Guinda é constituído pelas formações Bandeirinha, São João da Chapada, Sopa Brumadinho e Galho do Miguel. Almeida-Abreu (1993) e Silva (1995), sugeriram incluir a Formação Bandeirinha na base do Supergrupo Espinhaço. Esta unidade aflora de modo local entre Diamantina e Gouveia, sendo originalmente descrita como pertencente ao topo do Supergrupo Rio Paraúna (Fogaça et al. 1984). Ela é representada por quartzitos e conglomerados que apresentam fácies fluviais braided e eólica (Silva 1995), que estão em discordância angular com a Formação São João da Chapada. Esta discordância tem sido interpretada como relacionada às movimentações tectônicas sin-sedimentares ocorridas nas fases iniciais do rifte.

As formações São João da Chapada e Sopa Brumadinho representam um conjunto de metassedimentos com 200 até prováveis $1000 \mathrm{~m}$ de espessura, constituído por quartzitos finos a grossos, às vezes feldspáticos, ricos em estratificações cruzadas de pequeno a médio porte, com níveis de metapelitos e conglomerados em geral lenticulares, eventualmente diamantíferos (Pflug 1965, 1968, Schöll \& Fogaça 1979). Estas unidades foram depositadas em ambiente continental, com fácies de leque aluvial, fluvial braided, fan delta e lacustre, mostrando ainda passagens laterais para um sistema marinho raso (Garcia \& Uhlein 1987, Uhlein 1991, Martins Neto 1993, Almeida-Abreu 1993, 1995, Silva 1995). A morfologia da bacia era, provavelmente, de meio-gráben ou gráben assimétrico (Uhlein 1991, Martins-Neto 1993, Silva 1995), cujo embasamento mergulhava progressivamente para leste, consoante com a orientação preferencial das estratificações cruzadas. Atividade tectônica sinsedimentar ocorreu na forma de falhas normais direcionadas norte-sul, gerando horsts e grábens secundários. A sedimentação foi influenciada pelo tectonismo sedimentar, com rápidas e freqüentes variações faciológicas. $\mathrm{O}$ vulcanismo foi localizado, na forma de diques e sills de xistos verdes e, principalmente, hematita filitos, estes últimos de origem controvertida, provavelmente constituindo vulcanitos de filiação alcalina, altamente potássicos e com importante alteração metamórfica (Dussin 1994) ou intempérica (Knauer 1990, Knauer \& Schrank 1993). Os filitos hematíticos foram datados por $\mathrm{Pb} / \mathrm{Pb}$ em zircão, indicando idades de $1710 \mathrm{Ma}$ (Dossin et al. 1993), as quais devem representar a idade de sedimentação da porção basal do Supergrupo Espinhaço no setor meridional.

A Formação Galho do Miguel, que pode apresentar até 1000 $\mathrm{m}$ de espessura, é constituída por quartzitos finos, com elevado grau de maturidade, mostrando, às vezes, estratificações cruzadas gigantes, indicando o registro de depósitos cólicos costeiros (Dossin et al. 1987, Garcia \& Uhlein 1987). Ela foi depositada em condições de quiescência tectônica em relação as precedentes e com alargamento do sítio deposicional.

O Grupo Conselheiro Mata possui espessura em torno de 800-1000 m, sendo subdividido em cinco formações (Santa Rita, Córrego dos Borges, Córrego da Bandeira, Córrego Pereira e Rio Pardo Grande) que constituem alternâncias de siltitos e/ou pelitos com arenitos, geralmente finos a médios e bem selecionados (Pflug 1968, Schöll \& Fogaça 1979). As unidades estratigráficas representam ciclos transgressivos e regressivos de sistemas deposicionais transicionais, marinho raso (costeiro) a plataformal, com influência de ondas e marés (Garcia \&
Uhlein 1987). As formações são extensas e regulares, indicando estabilidade tectônica na bacia, em provável fase de subsidência térmica e flexural (Chang et al. 1988, Uhlein 1991, Martins Neto 1993, 1998) ou, mais provavelmente, como uma sinéclise de interior continental, sem vinculação com a fase rifte precedente. Dupont (199.5) descreve três seqüências deposicionais no Grupo Conselheiro Mata, com uma parte basal transgressiva e uma superior progradante, incluindo sedimentação desde plataforma marinha até fluvial.

Espinhaço Setentrional Na porção norte da Serra do Espinhaço aflora o Grupo Oliveira dos Brejinhos, constituído por quatro formações, apresentando cerca de $4000 \mathrm{~m}$ de espessura total: Pajeú, Bom Retiro, Fazendinha e Serra da Vereda (Schobbenhaus 1972, 1993, 1996). Danderfer (2000), em trabalho detalhado, identificou oito sintemas (seqüência estratigráfica limitada por discordância) na Serra do Espinhaço Setentrional, compreendendo cerca de $20.000 \mathrm{~m}$ de sedimentos. Eles foram denominados de Algodão, São Simão, Sapiranga, Pajeú, Bom Retiro, São Marcos, Sítio Novo e Santo Onofre. Visando uma uniformização da nomenclatura estratigráfica e favorecendo a simplificação afim de melhor descrever o rifte da Serra do Espinhaço Setentrional, serão utilizados os termos Formação Pajeú (compreendendo os quatro sintemas basais de Danderfer 2000), e as formações Bom Retiro, São Marcos, e Sítio Novo (Fig. 2B), conforme Schobbenhaus (1993, 1996) c Danderfer (2000). O sintema Santo Onofre é aqui considerado como equivalente estratigráfico do Grupo Macaúbas, sendo portanto relacionado ao Neoproterozóico (Schobbenhaus 1993, 1996, Danderfer 2000).

A Formação Pajeú compreende conglomerados com clastos de rochas cristalinas e arenitos feldspáticos de granulometria fina a grossa, com abundantes estratificações cruzadas. Rochas metavulcânicas ácidas e intermediárias (principalmente quartzo-pórfiros), afloram entre Boquira e Macaúbas com espessura entre 250 a $1000 \mathrm{~m}$ (Danderfer 2000). Para o topo predominam conglomerados com fragmentos de vulcânicas, arenitos arcoseanos médios a grossos mostrando estratificações cruzadas acanaladas e tabulares, e, no topo, ritmitos e pelitos com cerca de $1300 \mathrm{~m}$ de espessura. Segundo Danderfer \& Dardenne (1997) e Danderfer (2000), estas litofácies indicam o registro de sistemas de leques aluviais, fluvial braided (localmente sistema eólico) e lacustre. As paleocorrentes são orientadas para leste e sudeste. A Formação Pajeú possui cerca de 5000-7000m de sedimentos imaturos, com freqüentes variações laterais de fácies, vulcanismo ácido-intemediário, permitindo, assim, relacioná-la a uma fase sin-rifte (Schobbenhaus 1993, 1996, Danderfer 2000) com predomínio de subsidência mecânica, em função de falhas normais possivelmente orientadas para NNW. As espessuras das litofácies indicam altas taxas de subsidência, bem mais elevadas que as do Espinhaço Meridional.

A Formação Bom Retiro é constituída por quartzitos monótonos (quartzo-arenitos) finos a médios, com marcas onduladas e estratificações cruzadas de grande porte. Possui espessura superior a $500 \mathrm{~m}$ e suas litofácies são interpretadas como de origem eólica (Danderfer \& Dardenne 1997, Danderfer 2000). Esta sucessão foi depositada numa fase de quiescência tectônica, com subsidência baixa, talvez uma sinéclise interior (Danderfer 2000).

A Formação São Marcos é formada por arenitos de granulometria fina a média, às vezes feldspáticos, com intercalações de pelitos. A sedimentação foi em ambiente marinho 
raso a plataformal, com espessura média de $5000 \mathrm{~m}$, de lenta subsidência e variações eustáticas, provavelmente numa sinéclise continental (Danderfer 2000) ou fase pós-rifte, com subsidência passiva. A Formação Sítio Novo possui a maior expressão cartográfica, com largura em planta de 1 até $20 \mathrm{~km}$ e espessura em torno de $5000 \mathrm{~m}$, sendo constituída por arenitos com estratificações cruzadas, conglomerados, diamictitos, quartzitos com dumortierita e freqüentes intercalações de filitos, xistos e, localmente, mármores (Schobbenhaus 1993, Danderfer 2000). Representa sedimentação de leque aluvial associada com ambiente marinho raso a plataformal, caracterizando uma possível fase sin-rifte, com falhas normais orientadas para NNW, e predomínio de subsidência mecânica (Danderler 2000).

Mais ao sul, entre Licínio de Almeida e Caetité, Dominguez (1993) descreve, no Supergrupo Espinhaço, quartzitos flúvioeólicos, com direções de paleocorrentes para sul (SW e SE), superpostos por quartzitos com estratificações cruzadas de grande porte, de origem eólica, que são sucedidos por quartzitos com estratificação cruzada do tipo hummocky e intercalações de filitos grafitosos, depositados $\mathrm{em}$ ambiente marinho. Observa-se assim a mesma sucessão geral: arenitos fluviais, eólicos e marinhos, compondo o conjunto sedimentar do Supergrupo Espinhaço.

Chapada Diamantina O Supergrupo Espinhaço, na região da Chapada Diamantina (Fig. 2C), é subdividido em três grupos (Inda \& Barbosa 1978, Monteiro et al. 1984, Pedreira 1988, 1994, 1997, Dominguez 1993).

O Grupo Rio dos Remédios consiste em corpos lenticulares de metavulcânicas ácidas e intermediárias (riolitos, riodacitos, dacitos), rochas piroclásticas e intercalações de quartzitos depositados em ambiente desértico (Dominguez 1993, Pedreira 1997, Schobbenhaus, 1996). As vulcânicas foram datadas por Schobbenhaus et al. (1994), que obtiveram a idade de $1752 \mathrm{Ma}$ (U/Pb em zircão).

Em discordância sobre o Grupo Rio dos Remédios, ocorre o Grupo Paraguaçú, subdividido por Pedreira (1994), da base para o topo, nas formações Ouricuri do Ouro, Mangabeira e Guiné, com espessura total estimada entre 3 a $5 \mathrm{~km}$. A unidade basal é constituída por conglomerados polimíticos com clastos de arenitos, vulcânicas ácidas e rochas do embasamento, depositados em contexto de leque aluvial. A Formação Mangabeira é composta por quarzto-arenitos finos a médios com megaestratificações cruzadas, indicando ambiente desértico. Um gabro intrusivo na Formação Mangabeira foi datado por Babinski et al. (1999), que obtiveram a idade de $1514 \pm 22 \mathrm{Ma}$ (U/Pb em zircão). A Formação Guiné é constituída por arenitos, folhelhos e siltitos de ambiente deltáico. As paleocorrentes das fácies fluviais do Grupo Paraguaçú são direcionadas para sudeste (Dominguez 1993, Pedreira 1997).

A parte superior do Supergrupo Espinhaço na região da Chapada Diamantina corresponde ao Grupo Chapada Diamantina, constituído pelas Formações Tombador, Caboclo e Morro do Chapéu. A Formação Tombador, em discordância sobre o Grupo Paraguaçú, é constituída por quartzitos e conglomerados polimíticos (diamantíferos) relacionados a sistemas deposicionais de leque aluvial, fluvial braided e eólico. As paleocorrentes do sistema fluvial são direcionadas para oeste $\mathrm{e}$ sudoeste, caracterizando uma profunda reorganização paleogeográfica, com soerguimento de um alto estrutural a leste (Montes et al. 1981, Pedreira 1994, 1997, Schobbenhaus
1996). A Formação Caboclo compreende quartzitos, metapelitos e calcários estromatolíticos depositados em ambiente marinho raso, com transgressões e regressões, variando desde fácies de planície de marés a barras de plataforma. Calcários estromatolíticos foram datados por Babinski et al. (1993) sugerindo idades de $1140 \pm 140$ Ma pelo método $\mathrm{Pb} / \mathrm{Pb}$. Idade $\mathrm{Rb} / \mathrm{Sr}$ em pelitos anquimetamórficos indicam valores de $1290 \pm 52$ Ma para a diagênese da Formação Caboclo (BritoNeves et al. 1979). A Formação Morro do Chapéu, constituída por quartzitos e conglomerados depositados em ambientes flúvio-eólicos, é regressiva (Dominguez 1993, Pedreira 1997). Houve soerguimento do embasamento a leste da Chapada e exposição subaérea da plataforma marinha Caboclo, com erosão e preenchimento de vales incisos por sistemas fluviais entrelaçados direcionados para NW (Dominguez 1993). Conglomerados localmente diamantíferos, com seixos e matacões de até $30 \mathrm{~cm}$, constituídos por calcários, arenitos e pelitos, marcam a base da Formação Morro do Chapéu.

CORRELAÇÕES ESTRATIGRÁFICAS Correlações estratigráficas envolvendo os três domínios da Serra do Espinhaço têm sido tentadas por diversos autores (p. ex., Moraes \& Guimarães 1930, Torquato \& Fogaça 1981, Uhlein 1991, Schobbenhaus 1993, 1996, Silva 1996, Danderfer 2000), porém, na maioria dos casos, não foram considerados todos estes domínios integradamente, pela falta de dados sedimentológicos/estratigráficos e mesmo geocronológicos, envolvendo longas distâncias no Brasil Central.

A sedimentação ocorrida no domínio meridional da Serra do Espinhaço, cuja seção-tipo é reconhecida principalmente no paralelo de Diamantina, inclui três megaciclos deposicionais (M1, M2, M3), representados pelas formações Bandeirinha, São João da Chapada e Sopa Brumadinho (M1), Galho do Miguel (M2) e Grupo Conselheiro Mata (M3). O primeiro megaciclo envolve três fases de sedimentação sin-rifte, relacionada a cada uma das formações já citadas, separadas por discordâncias (Almeida-Abreu 1993, 1995, Silva 1995, Martins-Neto 1993, 1998). A sedimentação foi dominantemente continental com fase de subsidência mecânica, numa bacia compartimentada por grábens e horsts. Vulcanismo ácido e intermediário foi localmente muito importante, tanto a sul, em Conceição do Mato Dentro, como a norte, em Monte Azul (Fig. 3)

A Formação Galho do Miguel caracteriza o segundo megaciclo deposicional (M2), relacionado a sedimentação eólica costeira. Os sedimentos mostram grande espessura, definindo um estágio de estabilidade crustal, enquanto o Grupo Conselheiro Mata constitui o terceiro ciclo sedimentar (M3) com alternâncias de formações extensas e regulares, depositadas $\mathrm{em}$ ambiente marinho raso a transicional. Estas formações caracterizam ciclos menores transgressivos e regressivos, com estabilidade tectônica na bacia.

No Espinhaço Setentrional (Danderfer 2000), o megaciclo Ml está bem marcado nos principais atributos sedimentológicos da Formação Pajeú, com quartzitos médios a grossos, feldspáticos e conglomerados polimíticos, com paleocorrentes para sudeste. Estes sedimentos caracterizam a fase sin-rifte, onde não se conhecem depósitos diamantíferos. A Formação Bom Retiro marca o megaciclo M2, com sedimentos espessos de origem eólica. A Formação São Marcos representa o megaciclo M3, com sedimentação marinha rasa plataformal, sob contexto de estabilidade tectônica da bacia, em provável 
Tabela 1 - Correlações estratigráficas entre as diversas unidades do Supergrupo Espinhaço nas suas porções Meridional, Setentrional e Chapada Diamantina .Modificada de Danderfer (2000).

\begin{tabular}{|c|c|c|c|c|}
\hline $\begin{array}{c}\text { Ciclo } \\
\text { deposicional }\end{array}$ & $\begin{array}{c}\text { Idades } \\
\text { aproximadas }\end{array}$ & $\begin{array}{l}\text { Espinhaço } \\
\text { Meridional } \\
\text { (M G) }\end{array}$ & $\begin{array}{c}\text { Espinhaço } \\
\text { Setentrional } \\
\text { (BA) }\end{array}$ & $\begin{array}{c}\text { Chapada } \\
\text { Diam antina } \\
(\mathrm{BA})\end{array}$ \\
\hline M 3 & $1,2-1,5 \mathrm{Ga}$ & Gr. Conselheiro Mata & $\begin{array}{l}\text { Fm. Sítio Novo } \\
\text { Fm. São Marcos }\end{array}$ & $\begin{array}{c}\text { Gr. Chapada } \\
\text { Diamantina } \\
\text { Fm. Tombador } \\
0000\end{array}$ \\
\hline M2 & $1.5-1,7 \mathrm{Ga}$ & $\begin{array}{c}\text { Fm. Galho do Miguel } \\
\text { IIIVIII }\end{array}$ & $\begin{array}{l}\text { Fm. Bom Retiro } \\
\text { IIIVIII }\end{array}$ & $\begin{array}{c}\text { Fm Mangabeiras } \\
\text { Gr. Paraguaçu } \\
\text { IIIVIII }\end{array}$ \\
\hline M I & $1,70-1,75 \mathrm{Ga}$ & $\begin{array}{c}\text { Gr. Diamantina/Gr. } \\
\text { Guinda } \\
\text { Fm. Sopa-Brumadinho } \\
00000 \\
\wedge \wedge \wedge\end{array}$ & $\begin{array}{c}\text { Fm. Pajeú } \\
\wedge \wedge \wedge \wedge\end{array}$ & $\begin{array}{l}\text { Gr. Rio dos } \\
\text { Remédios } \\
\wedge \wedge \wedge \wedge\end{array}$ \\
\hline
\end{tabular}

fase de subsidência térmica e flexural. A base da Formação Sítio Novo mostra conglomerados e diamictitos que indicam reativação tectônica, com soerguimento e erosão das unidades inferiores. Para o topo, voltam as condições de sedimentação plataformal (Danderfer 2000).

Na região da Chapada Diamantina os megaciclos da Serra do Espinhaço não são facilmente identificáveis, provavelmente por constituir uma bacia independente. O Grupo Rio dos Remédios e a base do Grupo Paraguaçu representam uma sedimentação sin-rifte, enquanto o topo do Grupo Paraguaçu pode indicar uma fase transicional a pós-rifte. A Formação Tombador caracteriza uma importante reativação do rifte ensiálico, com soerguimento do embasamento a leste e inversão das paleocorrentes na bacia. A este soerguimento associamse, provavelmente, intrusões kimberlíticas/lamproíticas, as quais permitiram a acumulação de diamantes nos conglomerado polimíticos da sua porção basal. Uma nova fase sin-rifte poderia ser considerada em função da sedimentação da Formação Tombador. Esta reativação tectônica na região da Chapada Diamantina poderia ser correlacionável à base da Formação Sítio Novo, no Espinhaço Setentrional. Este evento, provavelmente extensional, deve ter ocorrido entre 1.5 a $1.4 \mathrm{Ga}$. A Formação Caboclo, depositada em ambiente marinho raso, pode representar uma fase pós-rifte ou de sinéclise na Chapada Diamantina. Uma nova reativação tectônica, com regressão, erosão da Formação Caboclo e sedimentação aluvial marca os depósitos areno-conglomeráticos da Formação Morro do Chapéu.

A tabela 1 sintetiza as correlações estratigráficas entre os três setores principais do Supergrupo Espinhaço em Minas Gerais e Bahia.

CONGLOMERADOS DIAMANTÍFEROS DO SUPERGRUPO ESPINHAÇO Depósitos das regiões de Diamantina e Grão Mogol, Minas Gerais Apesar dos dados a respeito da descoberta do diamante no Brasil variarem de acordo com os diversos historiadores, parece certo que as primeiras pedras tenham sido recuperadas no processo de mineração do ouro, iniciado no "Serro Frio" (região que faz parte da Serra do Espinhaço em Minas Gerais), ao final do século 17. Barbosa (1991) relata que esse encontro tenha ocorrido em 1714, no Córrego Pinheiro, ao norte do Arraial do Tejuco (atual cidade de Diamantina). O certo é que durante os subsequentes 15 anos a mineração do diamante já competia com a do ouro na região, sendo toda contrabandeada para a Europa, como se fosse proveniente da Índia. Em 1729, porém, o comerciante Bernardo da Fonseca Lobo, chegou a Portugal com uma partida de diamantes, que ofereceu de presente ao Rei, sendo por isso considerado o descobridor "oficial" dos diamantes em Minas Gerais. Em relação aos conglomerados da Formação SopaBrumadinho, as primeiras ocorrências constatadas como diamantíferas deram-se em meados do século 19 (Chaves 1997).

Na região de Diamantina, as rochas diamantíferas compreendem um conglomerado clasto-suportado e uma brecha quartzítica de matriz pelítica. O rudito clasto-suportado, denominado de "Conglomerado Sopa", ocorre no nível-E, porção média da Formação Sopa-Brumadinho, conforme Schöll \& Fogaça (1979) ou Membro Caldeirões, conforme AlmeidaAbreu (1995, 1996), correspondendo a uma rocha polimítica suportada pelo clasto, geralmente com seixos arredondados, em matriz arenosa. Apresenta geometria lenticular, com extensões entre 50 a $100 \mathrm{~m}$ e espessuras entre 2 e $4 \mathrm{~m}$, com contatos planos ou erosivos. É interpretado como sedimentação de fluxo de detritos e barras longitudinais em sistemas de leques aluviais, fluvial tipo braided ou ainda sedimentação de fan delta em ambiente lacustre (Almeida- Abreu 1995, Martins-Neto 1996).

A brecha quartzítica, possui seixos angulosos de quartzito róseo em matriz pelítica, geometria lenticular, com $2-5 \mathrm{~m}$ de espessura e dezenas de metros de extensão e geometria lenticular, incluída no Membro Campo Sampaio, topo da Formação Sopa-Brumadinho (Almeida-Abreu 1995, 1996). Estas rochas representam fluxos de detritos coesivos (mud-flows), relacionados a atividade tectônica extensional sin-sedimentar 
na bacia (fanglomerados), associados a atividade piroclástica (Haralyi et al. 1991, Almeida-Abreu 1996, Fleischer 1998).

Desde meados do século 19, ambos os tipos de conglomerados são lavrados em diversas áreas da região de Diamantina. Chaves (1997) designou tais áreas como "campos" diamantíferos, distribuídas ao longo de uma faixa com cerca de 100 km norte-sul desde o campo de São João da Chapada (ao norte) até o campo de Datas (ao sul). No sentido oeste-leste, o Conglomerado Sopa ocorre por cerca de $30 \mathrm{~km}$ desde a lavra dos Caldeirões, no campo de Sopa-Guinda (a oeste), até o campo de Extração (a leste). Nas áreas citadas, certas afinidades parecem ser comuns nos corpos conglomeráticos, tais como: geometria lenticular; clastos intraformacionais arredondados, a maioria de quartzitos, com diâmero de 5 a $30 \mathrm{~cm}$; aspecto caótico e sem estratificação; predomínio do clasto sobre a matriz. Outros fatores, porém, são variáveis de um campo para outro, como a natureza da matriz, composição e percentual relativo dos clastos, espessura dos corpos e ainda, o teor médio em diamantes (Chaves 1997).

Na região de Grão Mogol, conglomerados diamantíferos são conhecidos desde a mesma época que na região de Diamantina. Nesta região, a cerca de $300 \mathrm{~km}$ ao norte de Diamantina, o Supergrupo Espinhaço apresenta cerca de $400 \mathrm{~m}$ de espessura, sendo constituído por uma seqüência basal de quartzitos finos, com estratificações cruzadas de médio a grande porte, Formação Resplandecente (Karfunkel \& Karfunkel 1976) e por uma seqüência superior, representada por conglomerados diamantíferos e quartzitos médios a grossos, denominada de Formação Grão Mogol (Chaves et al. 1999). São conglomerados clastosuportados, com seixos quase exclusivamente de quartzitos, em matriz arenosa, representando sedimentos depositados sob condições fluviais, provavelmente representando barras longitudinais de cascalhos. A correlação destes conglomerados diamantíferos com os da Formação Sopa-Brumadinho não pode ser assumida. Segundo Chaves et al. (1999), os conglomerados de Grão-Mogol ocorrem estratigraficamente acima das fácies eólicas, possivelmente correlacionáveis à Formação Galho do Miguel, podendo representar sedimentação de wadis. Os diamantes poderiam ter sido retrabalhados a partir de hipotéticos depósitos da Formação Sopa-Brumadinho, já erodidos, ou representar nova e localizada fase de intrusões kimberlíticas/lamproíticas.

Depósitos da região da Chapada Diamantina, Bahia Diamantes e carbonados foram descobertos em aluviões da Serra do Sincorá (Chapada Diamantina Oriental) por volta de 1840 , desde então constituindo a principal riqueza mineral desta região. Atualmente a produção diamantífera encontra-se em acentuada decadência, sendo substituída, em parte, pelo ecoturismo. Entretanto, ao contrário do verificado na região de Diamantina (MG), as rochas conglomeráticas portadoras de diamantes nunca chegaram a ser efetivamente lavradas na Chapada Diamantina.

Os conglomerados diamantíferos da Chapada Diamantina ocorrem na Formação Tombador, entre Lençóis e Andaraí. Inicialmente, deve-se ressaltar que os principais mapeamentos executados nas proximidades de Andaraí e Lençóis (Montes 1977, Pedreira 1994, Misi \& Silva 1996) ressaltaram a existência de dois horizontes conglomeráticos distintos na Formação Tombador. O conglomerado basal, designado de "Unidade 2", possui espessura de $10 \mathrm{~m}$, aparecendo intercalado em quartzitos da mesma formação ("unidades 1 e 3"). Apresenta clastos extraformacionais (quartzo, quartzito verde) e intraformacionais (quartzitos, rochas efusivas e conglomerados), em matriz arenosa grossa (Montes 1977). O conglomerado superior ("Unidade 4"), caracteriza-se por apresentar coloração rosada pela predominância de clastos intraformacionais de quartzito róseos e vermelhos, apresentando, ainda, os outros mesmos tipos de clastos do nível basal, com espessura de aproximadamente $10 \mathrm{~m}$. Ambos os níveis conglomeráticos apresentam grande continuidade e representam deposição por fluxos de detritos e barras longitudinais em sistema de leque aluvial com retrabalhamento eólico (Montes 1977, Montes et al. 1981, Dominguez 1993, Misi \& Silva 1996, Pedreira 1997).

Mineralogia do diamante e considerações sobre às prováveis áreas fontes Os principais aspectos dos diamantes do Distrito de Diamantina foram estudados por Chaves (1997) e Chaves et al. (1998), a partir de amostragens representativas efetuadas em diversas áreas da região. Esses aspectos podem ser divididos em "primários", isto é, herdados de sua rocha fonte primária, e "secundários", adquiridos no(s) meio(s) sedimentar(es) posteriormente à erosão da(s) fonte(s) primária(s). A tabela 2 apresenta uma síntese das principais características mineralógicas dos diamantes da Serra do Espinhaço.

Entre as primárias, destacam-se: (1) peso médio baixo, variando entre $0,25 \mathrm{ct}$ em Diamantina e $0,15 \mathrm{ct}$ em Grão Mogol, sendo raríssimos os cristais de peso superior a $5 \mathrm{ct}$. Em Lençóis, tal média é difícil de ser aplicada, devido a presença comum de

Tabela 2 - Principais características primárias e secundárias, dadas em termos percentuais, dos diamantes da Serra do Espinhaço em suas porções Meridional (Diamantina e Grão Mogol) e Chapada Diamantina (Lençóis). (*) Inclui as formas de cristalização em rombododecaedros, octaedros, trioctaedros e transicionais entre estas.

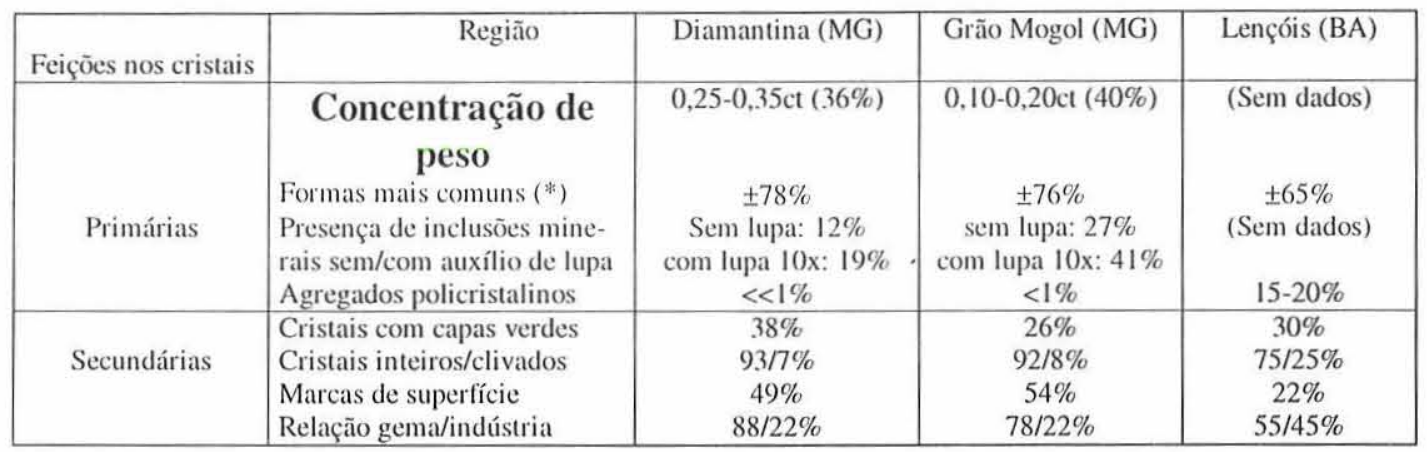


carbonados, os quais podem atingir altas quilatagens; (2) a maior parte $(>65 \%)$ das formas cristalinas observadas são monocristalinas como rombododecaedros e octaedros, além de transições entre ambos, e assim cristais geminados e agregados, além dos irregulares, são incomuns na Serra do Espinhaço; (3) os cubos e os agregados policristalinos conhecidos como borts estão ausentes no Espinhaço Meridional, sendo raríssimos em Grão Mogol e raros na Chapada Diamantina; (4) os diamantes coloridos (fancy diamonds) estão ausentes em Diamantina e Grão Mogol, enquanto na Chapada Diamantina eles ocorrem com certa frequiência; (5) a maioria dos cristais está isenta de inclusões minerais nas três regiões. Ainda em termos morfológicos, deve-se destacar a presença de carbonados nas populações de diamantes da Serra do Espinhaço, constituindo uma variedade policristalina de cor preta, típica na Chapada Diamantina (15-20\% das pedras extraídas), rara em Grão Mogol $(<0,1 \%)$ e provavelmente ausente em Diamantina. O "Carbonado do Sérgio", achado em Lençóis e pesando $3160 \mathrm{ct}$, é considerado o maior diamante do mundo.

Entre as características secundárias, verifica-se a existência de "capas" verdes nos diamantes, correspondendo a ínfimas películas esverdeadas, que podem recobrir o mineral desde parcial até totalmente. Em Diamantina, o percentual de cristais encapados varia entre 30\% (Sopa-Guinda, Datas e Extração) até $90 \%$ (São João da Chapada), podendo ser assumida a média regional de $38 \%$. Nos conglomerados de Grão Mogol e de Lençóis, os percentuais são semelhantes (26\% e $30 \%)$ aos de Diamantina (Chaves et al. 1998). A gênese dessas capas é atribuída à irradiação natural dos cristais por partículas-a dentro dos conglomerados, emitidas por minerais (ou soluções) ricas em tório e/ou urânio (Vance et al. 1973). Entre outros aspectos secundários importantes, observa-se o largo predomínio de cristais "inteiros" sobre cristais quebrados ao longo das clivagens ( $>75 \%)$, em todas as áreas da Serra do Espinhaço, e ainda a presença de marcas superficiais (impact marks), de modo característico nas regiões de Diamantina e Grão Mogol ( $\pm 50 \%$ das pedras). Como resultado de suas propriedades primárias e secundárias, destaca-se o predomínio de diamantes gemológicos em toda região do Espinhaço (Tabela 2).

O fato de não serem conhecidas rochas fontes primárias em toda extensão da Serra do Espinhaço, nem minerais indicadores destas, tem propiciado o surgimento de diversas discussões, principalmente no que se refere à natureza e posicionamento tectônico de tais fontes. Svisero (1978), estudando as inclusões minerais presentes nos diamantes da região de Diamantina, observou que as mesmas constituem assembléias mineralógicas comuns em rochas kimberlíticas. Chaves (1997) e Chaves et al. (1998), demonstraram que as principais características primárias e secundárias dos diamantes, apontam para uma fonte distante destes. Assim, nenhuma das características gerais das populações encontradas em fontes primárias, como nos kimberlitos e lamproítos da África, Rússia e Austrália, se verificam entre os diamantes da Serra do Espinhaço. A existência de populações de diamantes ricas em cristais de alta quilatagem e/ou com muitas inclusões, com cubos, borts e agregados cristalinos, além de cristais irregulares e fragmentos de clivagem, é típica de rochas primárias (ou aluviões próximos), pois os mesmos não resistem a transportes por longa distância (cf. Sutherland 1977). De outro modo, a verificação de aspectos mineralógicos comuns em populações transportadas no meio fluvial, como predomínio de formas inteiras e do hábito rombododecaédrico (neste, a presença de doze faces arredondadas auxilia no "rolamento" das pedras), são fortes argumentos a favor da hipótese de uma fonte distante, cujo resultado define a alta relação de diamantes gemológicos em comparação aos industriais.

Relacionando os dados de natureza geológica com os aspectos mineralógicos do diamante, algumas definições podem ser assumidas. Em Diamantina, as áreas fontes eram provavelmente distantes do sítio bacinal, a oeste do rifte, e devem ter sido cobertas pelos sedimentos da fase pós-rifte do Supergrupo Espinhaço (Fig. 4, Bl) e/ou pelas coberturas neoproterozóicas do Supergrupo São Francisco. Interessante observar que nesta última região parecem coexistir populações de diamantes de origens diversas, onde a presença local de cristais com maior quilatagem (como em Extração), pode significar uma população oriunda de intrusões mais próximas, possivelmente dentro do sítio bacinal. Segundo Almeida-Abreu (1996) e Fleischer (1998), a fonte dos diamantes das brechas fanglomeráticas do Membro Campo Sampaio situava-se próxima, dentro do sítio bacinal e relacionada a atividade piroclástica na bacia. Em Grão Mogol, pode-se constatar uma grande semelhança com as

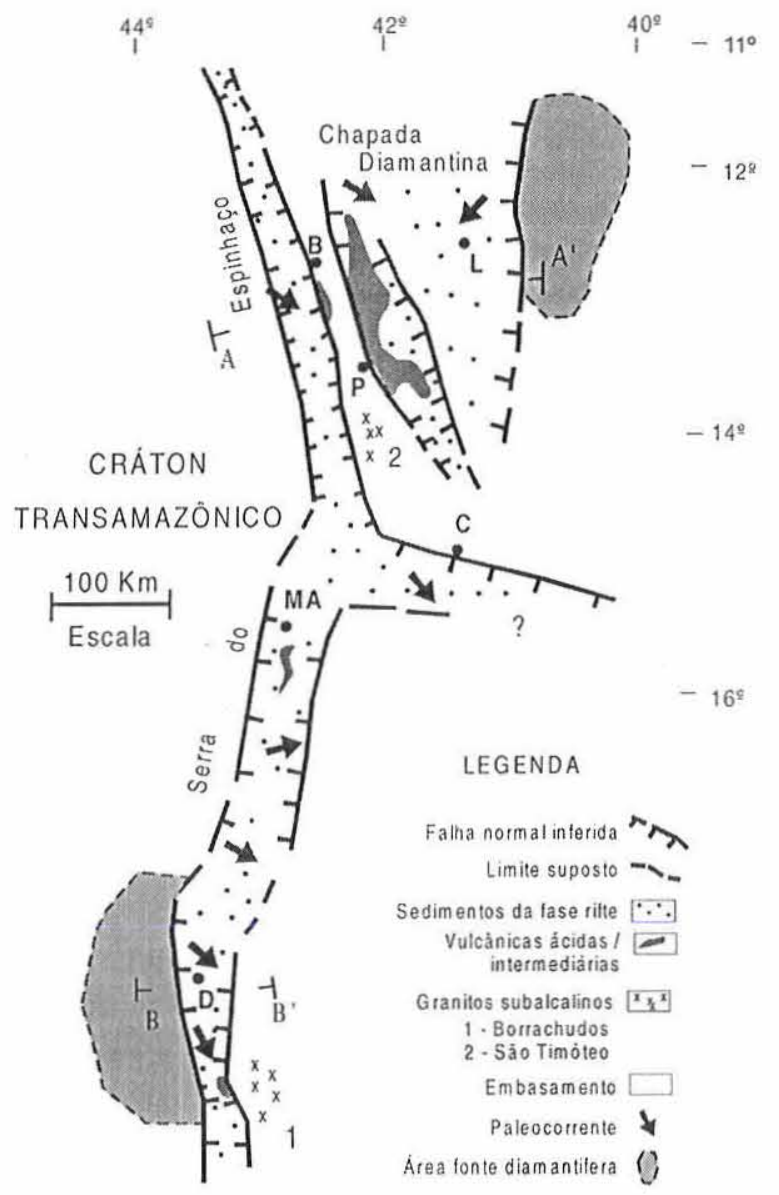

Figura 3 - Reconstituição paleogeográfica do rifte Paleol Mesoproterozóico do Supergrupo Espinhaço. Modificado de Uhlein \& Trompette (1998). Paleocorrentes segundo Uhlein (1991) e Dominguez. (1993). Indicação de cidades: B-Boquira, P-Paramirim, L-Lençóis, MA-Monte Azul; D-Diamantina; CCordeiros. A-A', B-B' localização das seções estruturais da Figura 4. 
principais feições geológicas e mineralógicas do diamante de Diamantina, ainda que existam diferenças significativas no aspecto estratigráfico. Entretanto é difícil de definir se estes diamantes representam erosão de conglomerados tipo-Sopa ou, mais provavelmente, um novo pulso de rochas kimberlíticas/ lamproíticas. Na Chapada Diamantina (Fig. 4, Al), a grande quantidade de clastos de quartzitos verdes encontrada nos conglomerados diamantíferos, demonstra que suas fontes afloravam a leste (nas proximidades da atual Serra de Jacobina ou seu prolongamento sul, conforme Montes et al. 1981), c situadas próximas do sítio bacinal devido a presença de carbonados, os quais, sendo agregados policristalinos, tendem a se pulverizar mais rapidamente no transporte fluvial. As ocorrências diamantíferas locais na Formação Morro do Chapéu poderiam representar erosão da Formação Tombador, ou, ainda, um outro pulso de magmatismo diamantífero.

EVOLUÇÃO GEODINÂMICA REGIONAL Inúmeros pesquisadores têm interpretado o Supergrupo Espinhaço, tanto em Minas Gerais como na Bahia, como um rifte ensiálico ou intracontinental. Destacam-se os trabalhos de Jardim de Sá (1981), Inda \& Barbosa (1978), Brito-Neves et al. (1979), Costa \& Inda (1982), Uhlein (1991), Schobbenhaus (1993), Dominguez (1993), Uhlein et al. (1995), Alkmim et al. (1993, 1996) e Danderfer (2000).

Na Chapada Diamantina, Pedreira (1994, 1997), sugere, inicialmente, a formação de uma bacia rifte (Grupo Rio dos Remédios), que evolui para margem continental com a Formação Guiné, topo do Grupo Paraguaçú, apresentando paleocorrentes para leste. Como consequência de um evento compressional Mesoproterozóico, teria ocorrido o fechamento da margem continental e formação de uma antefossa molássica (com sedimentação da Formação Tombador - Grupo Chapada Diamantina), e mudança no sentido das paleocorrentes, agora para SW.

Um modelo distinto é apresentado por Almeida-Abreu (1993, 1995) e Renger \& Almeida-Abreu (2000), que propõem, no Espinhaço Meridional, a formação de uma bacia rifte (1,75-1,70 Ga), mostrando evolução para uma margem passiva na porção sul/sudeste da Serra, com oceanização por volta de 1,65 Ga, além de inversão tectônica no Mesoproterozóico por volta de 1,5-1,2 Ga.

O rifteamento correspondente ao Supergrupo Espinhaço está relacionado a uma deformação extensional leste-oeste, com falhas normais aproximadamente norte-sul e noroestesudeste (Figs. 3 e 4). Este rifte Paleo a Mesoproterozóico é linear na Serra do Espinhaço, compreendendo um sistema estreito de grábens interligados ou não. Ao norte, na região de Oliveira dos Brejinhos (Schobbenhaus 1993, 1996), ele está melhor desenvolvido do que na porção sul da Serra do Espinhaço, em função da maior espessura dos conglomerados e fácies aluviais que marcam a fase sin-rifte, indicando assim maiores taxas de subsidência.

Rochas vulcânicas ácidas e intermediárias afloram nas regiões de Conceição do Mato Dentro (MG), Mato Verde-Monte Azul (MG), Paramirim (BA) e Macaúbas-Boquira (BA). Em Conceição do Mato Dentro estas vulcânicas ocorrem imbricadas tectonicamente em unidades basais do Supergrupo Espinhaço ou em sequência metassedimentar correlacionável ao Supergrupo Minas. Datações U/Pb forneceram idades de 1,77 Ga (Brito-Neves et al. 1979) e, mais recentemente, duas amostras indicaram idades em torno de 1,71 Ga (Machado $e t$

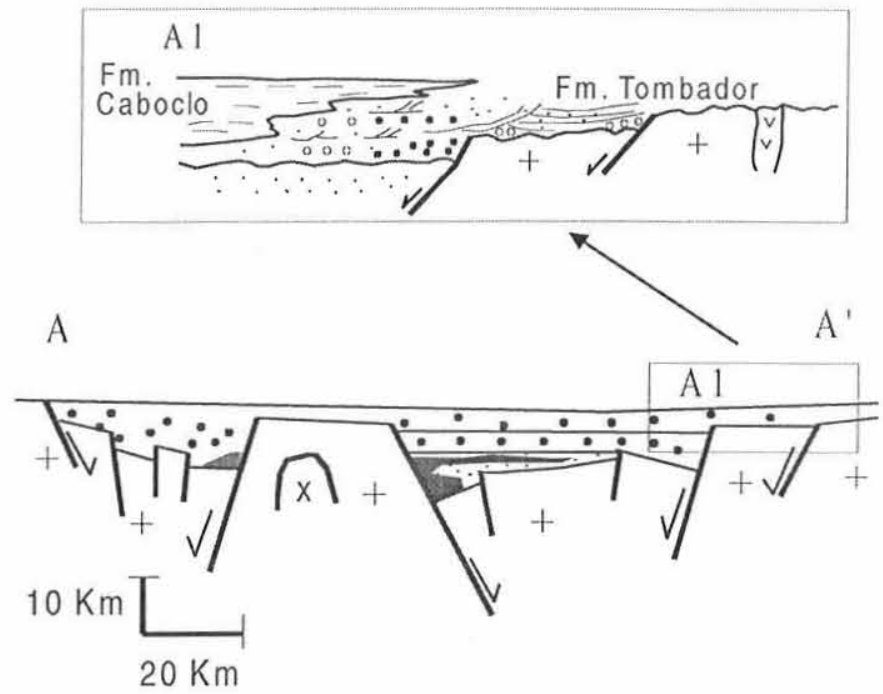

\section{Legenda}
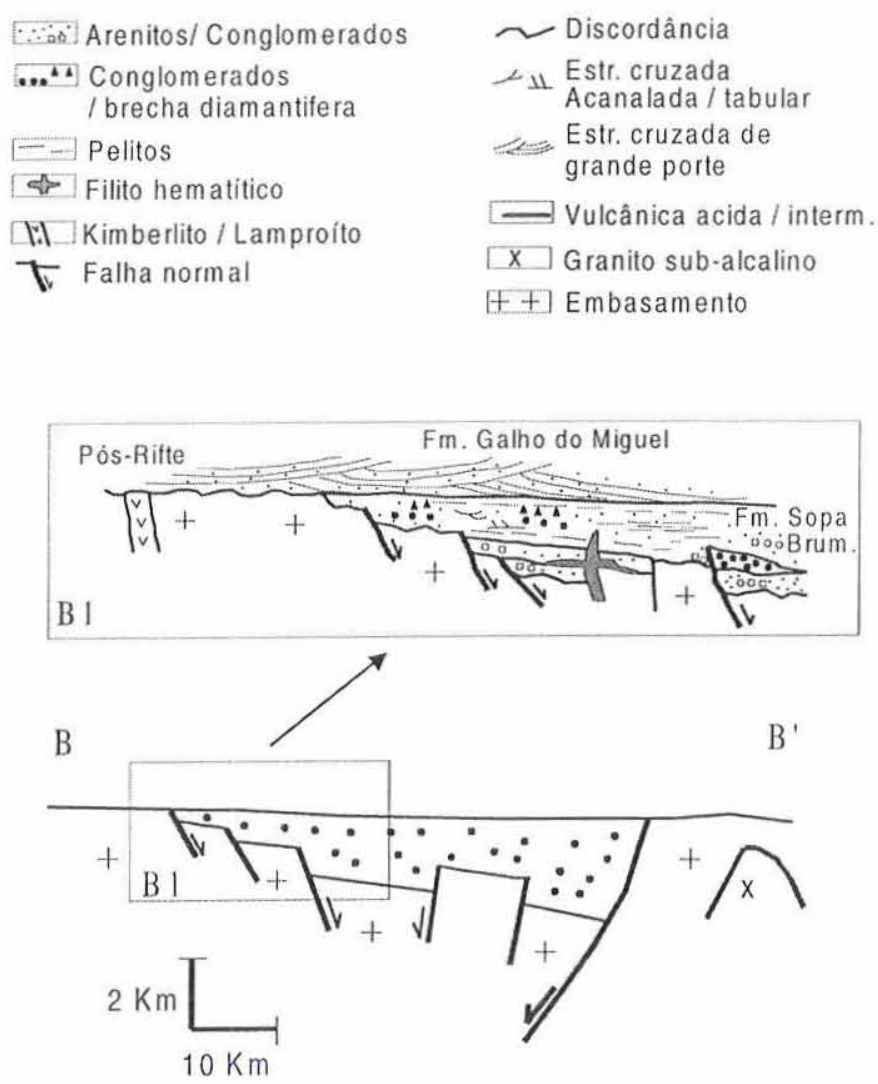

Figura 4 - Estrutura do rifte Espinhaço e ambiência sedimentar dos conglomerados diamantíferos de Lençóis-BA (Quadro Al) e de Diamantina (Quadro BI). Seção AA'modificada de Alkmim et al .(1993) e Pedreira (1997). Seção B-B' modificada de Uhlein (1991) e Silva (1995).

al. 1989). Em Mato Verde-Monte Azul afloram rochas vulcânicas ácidas-intermediárias (riolitos a riodacitos) com intercalações de aglomerados, tufos, diversos tipos de plutonitos e rochas detríticas, como conglomerados e quartzitos (Menezes Filho 1980). Uhlein (1991) apresentou alguns dados químicos sobre tais rochas, considerando-as como subalcalinas. 
Traquiandesitos desta unidade foram datados por M. Babinski (USP), indicando idades $\mathrm{U} / \mathrm{Pb}$ de $1,75 \mathrm{Ga}$ (informação verbal). Na região de Paramirim (Chapada Diamantina Ocidental), o magmatismo varia de dacitos a riolitos, mostrando afinidades metaluminosa e subalcalina, enquanto na região entre Boquira e Macaúbas, as rochas variam de riolitos a traquitos e são peralcalinas, com afinidade comendítica (McReath et al. 1981). A gênese dessas rochas relaciona-se à formação de domos no processo de rifteamento da crosta continental, possivelmente por anatexia crustal (McReath et al. 1981, Jardimde-Sá 1981).

As rochas vulcânicas acima descritas associam-se a plutons graníticos subalcalinos, denominados de "Borrachudos", que afloram a leste da Serra do Espinhaço Meridional (Dossin et al. 1993, Dussin 2000) e também em São Timóteo, entre Caetité e Paramirim, Bahia (Cordani et al. 1992). Esses plutonitos são intrusivos no embasamento do rifte e datados em 1,73 Ga (Cordani et al. 1992, Dossin et al. 1993), sendo aproximadamente contemporâneos à extensão continental e estariam relacionados ao processo de individualização do rifte. Neste contexto, esforços distensivos intraplaca, provavelmente ao longo de antigas linhas de fraqueza de idades Transamazônicas, teriam causado o adelgaçamento da litosfera permitindo que o manto e a astenosfera, sob o rifte, estivesse mais próximo da superfície (Fig. 4).

O rifte continental da Serra do Espinhaço é preenchido por sequências sin-rifte e pós-rifte (Chang et al. 1988, Uhlein 1991, Dominguez 1993, Schobbenhaus 1993, Martins-Neto 1995, 1998). A bacia de sedimentação foi do tipo rifte ensiálico ou intracontinental, com possíveis fases tectônicas do tipo sinrifte, com subsidência mecânica, e pós-rifte, com subsidência flexural. Durante a fase sin-rifte, ocorreram processos de subsidência mecânica devido ao afinamento crustal e ruptura da crosta por estiramento, que controlaram a evolução estratigráfica da bacia. O desenvolvimento de discordâncias e deposição de sedimentos aluviais foi controlada pelo tectonismo extensional. Esta fase é caracterizada pelo tectonismo ativo (falha normal), subsidência mecânica e sedimentação em pulsos, gerando discordâncias angulares e erosivas entre unidades sedimentares. A fase pós-rifte está relacionada, provavelmente, a subsidência flexural térmica, devido a contração termal (adensamento) da litosfera durante seu resfriamento. Ocorre então, estabilidade tectônica, quando a sedimentação foi controlada por variações no nível dos mares.

A sequência sin-rifte é constituída por quartzitos geralmente mal selecionados, com estratificações cruzadas e ainda, por conglomerados e pelitos. Foram depositados em sistemas fluviais tipo braided e leques aluviais, que podem se interdigitar com fácies de ambiente marinho ou lacustre. Atividade de blocos de falhas subdividiu a bacia num complexo sistema de horsts e grabens. As paleocorrentes deste sistema fluvial orientam-se para sudeste. O rifte da Serrra do Espinhaço possui uma geometria de meio-graben ou de gráben assimétrico, bem caracterizado na porção sul da bacia (Silva 1995). O embasamento mergulha progressivamente para leste, atestado pelas paleocorrentes do sistema fluvial e aumento das espessuras das litofácies neste sentido. A sedimentação foi controlada por altos locais do embasamento, com rápidas e freqüentes variações faciológicas. É possível caracterizar uma borda flexural, geralmente a oeste, com falhas de pequeno rejeito, pouca subsidência e pequena espessura do registro sedimentar, além de uma falha de borda principal (master fault) situada a leste na Serra do Espinhaço (Fig. 4). A borda flexural constitui um monoclinal ou rampa que mergulha contra a borda falhada principal (Silva 1995, Martins-Neto 1998). Falhas antitéticas e sintéticas, com rotação de blocos principalmente no sentido anti-horário, devem representar a estrutura fundamental do rifte Espinhaço. Estas falhas teriam geometria planar e alto ângulo $\left(>60^{\circ}\right)$ devido a amplitude relativamente pequena da distensão crustal.

A seqüência pós-rifte é formada por quartzitos finos, bem selecionados, metassiltitos e filitos ou metargilitos, com intercalações eventuais de rochas carbonáticas, depositados em ambiente marinho a transicionais, com formações extensas e regulares, associadas a transgressões e regressões, em regime de estabilidade tectônica na bacia. Esta sequiência é transgressiva sobre os limites do rifte, sendo interpretada como resultado do relaxamento termal, no final do processo de rifteamento, onde predominam subsidências térmica e flexural, possivelmente associada ao enrijecimento e esfriamento da litosfera. A longa história geocronológica da bacia Espinhaço sugere, também, que unidades de topo possam representar a evolução de bacias intracratônicas tipo sinéclise de interior continental, sem vinculação com fases rifte precedentes.

Na Serra do Espinhaço Setentrional e na Chapada Diamantina ocorre, no topo, recorrência da fase sin-rifte, marcada pelos conglomerados e quartzitos com estratificação cruzada das formações Sítio Novo e Tombador. Representam uma importante fase de reativação tectônica, através de um pulso extensional no Mesoproterozóico. Formaram-se falhas normais, com soerguimentos de blocos do embasamento e erosão de unidades sdimentares mais antigas, expansão da bacia sedimentar (onlap) e sedimentação detrítica importante (fácies de leques aluviais).

O rifte da Serra do Espinhaço apresenta uma possível ramificação ortogonal, leste-oeste, situada aproximadamente na divisa entre Minas Gerais e Bahia. Está relacionada à metassedimentos do Supergrupo Espinhaço na região do Alto Rio Pardo (Lima et al. 1981, Uhlein 1991), representada por quartzitos feldspáticos com estratificações cruzadas bem preservadas, conglomerados e biotita-xistos, metamorfizados na fácies anfibolito. As paleocorrentes são direcionadas para sul e sudeste. Esses metassedimentos afloram nas serras de Inhaúmas e Caititú, ao sul das localidades de Cordeiros e Tremedal (BA), mostrando feições homoclinais de direção E-W e mergulhos para sul (Lima et al. 1981, Uhlein 1991).

Zonas de fraqueza relacionadas a falhas normais do rifte Espinhaço provavelmente condicionaram as intrusões kimberlíticas/lamproíticas (Fleischer 1998, White et al. 1995). Isto ocorreu em duas importantes fases diferenciadas no tempo e no espaço: a oeste de Diamantina-Serra do Espinhaço Meridional, no Paleoproterozóico (1,73 a 1,71 Ga) e a leste/ nordeste de Lençóis, na Chapada Diamantina, no Mesoproterozóico (1,5 a 1,3 Ga).

CONCLUSÃO Dados estratigráficos, sedimentológicos, estruturais e geocronológicos apresentados de maneira integrada permitiram correlacionar as unidades do Supergrupo Espinhaço nos Estados de Minas Gerais e Bahia. A evolução tectono-sedimentar da Bacia Espinhaço é sugestiva de um rifte intracratônico, com fase de rifteamento inicial, subsidência mecânica e vulcanismo/plutonismo alcalino. A sedimentação foi principalmente continental, com leques aluviais, fluvial braided e eólico, que se alternam com sedimentos lacustres, 
deltáicos ou marinhos rasos. Estes últimos marcam fases de estabilidade tectônica na bacia (fase pós-rifte), provavelmente devido a subsidência flexural, quando a sedimentação foi controlada pela variação do nível dos mares. No Espinhaço Baiano, uma importante fase de reativação tectônica, com pulso extensional, sedimentação de leques aluviais, soerguimento de blocos do Embasamento, com intrusões de rochas portadoras de diamantes, pode ser reconhecido nas bases das formações Sítio Novo e Tombador. Duas fases de intrusões kimberlíticas/lamproíticas são sugeridas. A primeira, relacio- nada aos diamantes detríticos da Formação Sopa-Brumadinho (MG), deve ter ocorrido no intervalo 1,73-1,70 Ga. A segunda, relacionada aos diamantes detríticos da Formação Tombador (BA), provavelmente ocorreu no intervalo 1,4-1,2 $\mathrm{Ga}$. As intrusões portadoras de diamante devem se relacionar a pulsos do rifteamento e a localização das prováveis áreasfontes foram deduzidas a partir do sentido das paleocorrentes.

Agradecimentos Aos revisores da RBG pelas sugestões ao manuscrito.

\section{Referências}

Alkmim F.F., Brito-Neves B.B., Alves J.A.C. 1993. Arcabouço tectônico do Cráton do São Francisco - uma revisão. In: Dominguez J.M.L., Misi A. (eds.), O Cráton do São Francisco. Reunião preparatória do II Simpósio sobre o Cráton do São Francisco. Salvador, SBG/Núcleo BA-SE/SGM/ CNPq, p.45-62.

Alkmim F.F., Chemale Jr. F., Endo I. 1996. A deformação das cobreturas proterozóicas do Cráton do São Francisco e o seu significado tectônico. Revista da Escola de Minas, 49: 22-38.

Almeida-Abreu P.A. 1993. A evolução geodinâmica da Serra do Espinhaço Meridional, Minas Gerais, Brasil. Freiburg, 150 p. (Tese de Doutoramento, Albert-Ludwigs-Universität).

Almeida-Abreu P.A. 1995. O Supergrupo Espinhaço da Serra do Espinhaço Meridional, Minas Gerais: o rifte, a bacia e o orógeno. Geonomos, 3: 1-18.

Almeida-Abreu P.A. 1996. O caminho das pedras. Geonomos, 4: 77-93.

Babinski M., Van Schınus W.R., Chemale Jr. F., Brito-Neves B.B., Rocha A.J.D. 1993. Idade isocrônica $\mathrm{Pb} / \mathrm{Pb}$ em rochas carbonáticas da Formação Caboclo, em Morro do Chapéu-BA. In: Il Simpósio do Cráton do São Francisco, Salvador, 1993. Anais... Salvador, SBG/SGM, vol. I, p.160-163.

Babinski M., Pedreira A.J., Brito-Neves B.B., Van Schmus W.R. 1999. Contribuiçĩo à Geocronologia da Chapada Diamantina. In: VII SNET - Simp. Nacional de Estudos Tectônicos, Anais..., Sessão 2, p.118-120. Lençóis-BA.

Barbosa O. 1991. Diamante no Brasil: histórico, ocorrência, prospecçĩo c lavra. Rio de Janeiro, CPRM, 102p.

Brito-Neves B.B., Kawashita K., Cordani U.G., Delhal J. 1979. A evolução geocronológica da Cordilheira do Espinhaço: dados novos e integração. Revista Brasileira de Geociências, 9: 71-85.

Brito-Neves B.B., Sá J.M.,Nilson A.A., Botelho N.F. 1995. A tafrogênese estateriana dos blocos paleoproterozóicos da América do Sul e processos subsequentes. Geonomos, 3: 1-21.

Chang H.K., Miranda F.P., Magalhães L., Alkmim F.F. 1988. Considerações sobre a evolução tectônica da Bacia do São Francisco. In : Congresso Brasileiro de Geologia, 35. Belém, 1988. Anais... Belém, SBG, v. 5, p. 2076 2090.

Chaves M.L.S.C. 1997. Geologia e mineralogia do diamante da Serra do Espinhaço em Minas Gerais. São Paulo, 289p. (Tese de Doutoramento, IG/ Univ. São Paulo).

Chaves M.L.S.C., Karfunkel J., Svisero D.P. 1998. Sobre a polêmica da origem do diamante na Serra do Espinhaço (Minas Gerais): um enfoque mineralógico. Revista Brasileira de Geociências, 28:285-294.

Chaves M.L.S.C., Karfunkel J., Addad J, 1999. Geologia da região diamantífera de Grão Mogol, Minas Gerais. Geociências, 18:129-155.

Cordani U.G., Iyer S.S., Taylor P.N., Kawashita K., Sato K., Mcreath I. 1992. Pb$\mathrm{Pb}, \mathrm{Rb}-\mathrm{Sr}$ and $\mathrm{K}-\mathrm{Ar}$ systematics of the Lagoa Real uranium province (south-central Bahia, Brazil) and the Espinhaço Cycle (c.a 1,5-1,0 Ga). Journal of South American Earth Sciences, 5:33-46.

Costa L.A.M., Inda H.A.V. 1982. O aulacógeno do Espinhaço. Ciências da Terra, $2: 13-18$.

Danderfer A., Lagoeiro L.E., Alkmim F.F. 1993. O sistema de dobramentos e empurrões da Chapada Diamantina $(B A)$ : registro da inversão do aulacógeno do Espinhaço no decorrer do evento Brasiliano. In: Simpósio sobre o Cráton do São Francisco, 2, Salvador, 1993. Anais... Salvador,
SBG/SGM, vol. 1, p.197-199.

Danderfer A., Dardenne M.A. 1997. Resultados preliminares sobre a evoluçĩo estratigráfica da tectonossequência Pajeú no extremo nordeste do Espinhaço Setentrional, região Central do Estado da Bahia. In : Simpósio de Geologia de Minas Gerais, 9. Ouro Preto, 1997. Anais... Ouro Preto, SBG/MG, p.88-90.

Danderfer A. 2000. Geologia sedimentar e evolução tectônica do Espinhaço Setentrional, Estado da Bahia. Brasília, 494p. (Tese de Doutoramento, IGUnB).

Dominguez J.M.L. 1993. As coberturas do Cráton do São Francisco : uma abordagem do ponto de vista da análise de bacias. In : Dominguez J.M.L. \& Misi A. (eds), O Cráton do São Francisco. Reunião preparatória do II Simp. Cráton do São Francisco. Salvador, SBG/Núcleo BA-SE/SGM/CNPq. p.137-159.

Dossin I.A., Garcia AI.V., Uhlein A., Dardenne M.A., Dossin T.M. 1987. Fácies eólico na Formação Galho do Miguel (MG). In: Simp. sobre Sistemas Deposicionais no Pré-cambriano, Ouro Preto, 1987. Anais... Ouro Preto, SBG-MG, p.8.5-96.

Dossin I.A., Dossin T.M., Chaves M.L.S.C. 1990. Compartimentação estratigráfica do Supergrupo Espinhaço em Minas Gerais - os grupos Diamantina e Conselheiro Mata. Revista Brasileira de Geoiências, 20:178186.

Dossin I.A., Dossin T.N., Charvet J., Cocherie A., Rossi P. 1993. Single-zircon dating by step-wise Pb-evaporation of Middle Proterozoic magmatism in the Espinhaço range, southeastern São Francisco Craton (Minas Gerais, Brazil). In : Simpósio Cráton do São Francisco, 2, Salvador, 1993, Anais... Salvador, SBG/SGM, v.1, p. 39-42.

Dupont H.J.B. 1995. O Grupo Conselheiro Mata no seu quadro paleogeográfico e estratigráfico. Bol. Soc. Bras. Geol., Núcleo Minas Gerais, 13: 9-10.

Dussin T.M. 1994. Associations plutono-volcaniques de l'Espinhaço Méridional (SE-Brésil): un exemple d'évolution de la croûte protérozoïque. Orleans, 177 p. (These de Docteurement, Universite d'Orleans).

Dussin T.M. 2000 A tectônica extensional paleoproterozóica na borda sudeste do Cráton do São Francisco (SE Brasil): geoquímica e petrologia das metaígneas. Gconomos, 8: 63-68.

Fleischer R. 1998. A rift model for the sedimentary diamond deposits of Brazil. Mineralium Deposita, 33:238-254.

Fogaça A.C.C., Almeida-Abreu P.A., Schorscher J.H.D. 1984. Estratigrafia da sequiência supracrustal arquena na porção mediana-central da Serra do Espinhaço, Minas Gerais. In: Congresso Brasileiro de Geologia, 33, Rio de Janeiro, 1984. Anais... Rio de Janeiro, SBG, v.6, p.2654-2667.

Garcia A.J.V., Uhlein A. 1987. Sistemas deposicionais do Supergrupo Espinhaço na regiāo de Diamantina (MG). In: Simp. sobre Sistemas Deposicionais no Pré-Cambriano, Ouro Preto, 1987. Anais... Ouro Preto, SBG-MG, p.113135.

Haralyi N., Hasui Y., Morales N. 1991. O diamante Pré-Cambriano da Serra do Espinhaço, MG. In: Schobbenhaus C. (ed.), Principais Depósitos Minerais do Brasil, DNPM-CPRM, Brasília, IV-A, p.209-222.

Inda H., Barbosa J.F. 1978. Texto explicativo para o mapa geológico do Estado da Bahia, esc. 1:1000000. CPM/SME/CBPM, Salvador, 137p.

Jardim-de-Sá E.F. 1981. A Chapada Diamantina e a Faixa Santo Onofre: um 
exemplo de tectônica intraplaca no Proterozóico Médio do Cráton do São Francisco. In: Geologia e Recursos Minerais do Estado da Bahia. Inda H.A.V., Marinho M.M., Duarte F.R. (eds.), CPM, Salvador, vol.4:111-120.

Karfunkel B., Karfunkel J. 1976. Geologia da Serra do Espinhaço no norte de Minas Gerais (Itacambira - Botumirim). In: Congresso Brasileiro de Geologia, 29, Ouro Preto, 1976. Anais... Ouro Preto, SBG, v.2, p.169-178.

Knauer L.G. 1990. Evolução geológica do Pré-Cambriano da porção centro-leste da Serra do Espinhaço Meridional e metalogênese associada. Campinas, 298p. (Diss. de Mestrado, Dep. Geociências/Unicamp).

Knauer L.G., Schrank A. 1993. A origem dos filitos hematíticos da Serra do Espinhaço Meridional, Minas Gerais. Geonomos, 1:33-38.

Lima M.I.C., Fonseca, E.G.da, Oliveira, E.P.de, Ghignone, J.I., Rocha, R.M. Carmo, U.F.do, Silva, J.M.R. da, Siga Jr., O.1981. Geologia. In: Projeto RadamBrasil. Folha SD. 24 - Salvador. Levantamento de Recursos Naturais, 24, MME, Rio de Janeiro.

Machado N., Schrank A., Abreu F.R., Knauer L.G., Almeida-Abreu P.A. 1989. Resultados preliminares da geocronologia U-Pb na Serra do Espinhaço Meridional. Anais V Simp. Geologia de Minas Gerais, SBG- Núcleo MG, Bol. 10, p.171-174, Belo Horizonte.

Martins-Neto M.A. 1993. The sedimentary evolution of a Proterozoic rift basin: the basal Espinhaço Supergroup, Southern Serra do Espinhaço, Minas Gerais, Brazil. Freiburg. 155p. (Tese de Doutoramento, Albert-LudwigsUniversität).

Martins-Neto M.A. 1995. A evoluçāo tectônica da bacia Espinhaço no Estado de Minas Gerais. In: V SNET - Simp. Nacional Estudos Tectônicos, Gramado (RS), Anais..., p.287-289.

Martins-Neto M.A. 1996 Lacustrine fan-deltaic sedimentation in a Proterozoic rift basin: the Sopa-Brumadinho Tectonosequence, southeastern Brazil. Sedimentary Geology, 106:65-96

Martins-Neto M.A. 1998. O Supergrupo Espinhaço em Minas Gerais: registro de uma bacia rifte-sag do Paleo/Mesoproterozóico. Revista Brasileira de Geociências, 28:151-168.

Mcreath 1., Jardim-de-Sá, E., Fryer B.J, 1981. As vulcânicas ácidas proterozóicas da regiâo da bacia do Rio Paramirim-BA. In: Geologia e Recursos Minerais do Estado da Bahia, Inda H.A.V., Duarte F.B. (eds.) CPM, Salvador, $\operatorname{vol} 4: 121-134$

Menezes Filho N.R. 1980. Sequencia vulcano/vulcanoclástica da Serra do Riacho Seco (Monte Azul, MG)-Supergrupo Espinhaço. In: Congresso Brasileiro de Geologia, 30, Balneário Camboriú, 1980. Anais... Balneário Camboriú, Soc. Bras. Geol., vol.4, p.2104-2118.

Misi A., Silva M.G. 1996. Chapada Diamantina Oriental-Bahia: Geologia e Depósitos Minerais. Salvador, SGM, 194p. (Série Roteiros Geológicos).

Monteiro M.D., Carvalho M.P., Conceição Filho V.M. 1984. Caracterização faciológica e sistemas deposicionais do Grupo Chapada Diamantina. In: Congresso Brasileiro de Geologia, 33, Rio de Janeiro, 1984. Anais... Rio de Janeiro, Soc. Bras. Geol., p.1090-1105.

Montes M.L. 1977. Os conglomerados diamantíferos da Chapada Diamantina Bahia, Brasil. Brasília, 101p. (Tese de Mestrado, IG-UnB).

Montes A.L.S., Montes M.L., Dardenne M.A. 1981. A região da Serra da Jacobina, um paleorelevo ativo durante a sedimentação dos Grupos Chapada Diamantina e Bambuí. In: Simpósio Sobre o Cráton do São Francisco e suas faixas marginais, Salvador, 1979, Anais... Salvador, CPM/ Soc. Bras. Geol., p.79-86.

Moraes L.J., Guimarães D. 1930. Geologia da região diamantífera do norte de Minas Gerais. Anais Academia Brasileira de Ciências, 2:153-186.

Pedreira A.J. 1988. Sequências deposicionais no Pré-Cambriano: exemplo da Chapada Diamantina Oriental. In: Congresso Brasileiro de Geologia, 35 , Belém, 1988. Anais...Belém, SBG, vol.2, p. 648-6.59.

Pedreira A.J. 1994. O Supergrupo Espinhaço na Chapada Diamantina CentroOriental, Bahia: sedimentologia, estratigralia e tectônica. São Paulo, 126p). (Tese de Doutoramento, IG-USP).

Pedreira A.J. 1997. Sistemas deposicionais da Chapada Diamantina Centro-Oriental, Bahia. Revista Brasileira de Geociências, 27:229-240.

Pflug R. 1965. A geologia da parte meridional da Serra do Espinhaço e zonas adjacentes, Minas Gerais. Rio de Janeiro, DNPM/DGM, 55p). (Boletim 226).
Pflug R. 1968. Observações sobre a estratigrafia da Série Minas na região de Diamantina, Minas Gerais. Rio de Janeiro, DNPM/DGM, 20p. (Notas Preliminares e Estudos 142).

Pflug R., Schobbenhaus C., Renger F. 1969. Contribuição à geotectônica do Brasil Oriental. Recife, SUDENE, 57p. (Série Especial 9).

Renger F.E., Almeida-Abreu P.A 2000. The southern Espinhaço Mountain Range: its geodynamic evolution and diamond mineralization, Minas Gerais State, Eastern Brazil. In: 31 st International Geological Congress, PostCongress field trip, Rio de Janeiro, 36p.

Schobbenhaus C. 1972. Relatório geral sobre a geologia da região setentrional da Serra do Espinhaço, Bahia Central. Recife, SUDENE, 112p. (Série Geologia Regional 19).

Schobbenhaus C. 1993. O Proterozóico Médio no Brasil com ênfase à Região Centro-Leste. Freiburg, 166p. (Tese de Doutoramento, Albert-LudwigsUniversität).

Schobbenhaus C. 1996. As tafrogêneses superpostas Espinhaço e Santo Onofre. Estado da Bahia: revisão e novas propostas. Revista Brasileira de Geociências, 26:265-276.

Schobbenhaus C., Hoppe A., Baumann A., Lorck A. 1994. Idade U-Pb do vulcanismo Rio dos Remédios, Chapada Diamantina, Bahia. In: Congresso Brasileiro de Geologia, 38, Balneário de Camboriú, 1994. Anais... Balneário Camboriú, SBG-DNPM-CPRM, v.2, p.397-399.

Schöll W.U., Fogaça A.C.C. 1979. Estratigrafia da Serra do Espinhaço na região de Diamantina (MG). In: Simpósio de Geologia de Minas Gerais, 1, Diamantina, 1979. Atas... Diamantina, SBG-MG, p.55-73.

Silva R.R. 1995. Sequence stratigraphy and depositional systems of the Lower Espinhaço Supergroup, in the area between Diamantina and Gouveia, Minas Gerais, Brazil. Freiburg, 145p. (Tese de Doutoramento, Albert-Ludwigs Universität).

Silva R.R. 1996. Correlation of the depositional sequences of the Proterozoic Espinhaço/São Francisco basin system, in Minas Gerais and Bahia states, Brazil. In: Congresso Brasileiro de Geologia, 39, Salvador, 1996. Anais... Salvador, SBG, v.6, p.142-144.

Sutherland D.G. 1977. The transport and sorting of diamonds by fluvial and marine processes. Economic Geology, 84:1613-1620.

Svisero D.P. 1978. Composição química, origem e significado geológico de inclusões minerais em diamantes do Brasil. São Paulo, 165p. (Tese de Livre Docência. IG/Univ. São Paulo).

Torquato J.F.R., Fogaça A.C.C. 1981. Correlação entre o Supergrupo Espinhaço no Brasil, o Grupo Chela em Angola c as Formações Nosib e Khoabendus da Namíbia. In: I Simp. Sobre o Cráton do São Francisco e suas faixas marginais. Anais... Salvador, SBG-Núcleo BA, p.87-98.

Uhlein A. 1991. Transição craton-faixa dobrada: um exemplo do Cráton do São Francisco e da Faixa Araçuaí (Ciclo Brasiliano) no Estado de Minas Gerais. Aspectos estratigráficos e estruturais. São Paulo, 295p. (Tese de Doutoramento, IG/Univ. de São Paulo).

Uhlein A., Pedreira A.J. 1989. Considerações sobre a geologia estrutural, tectônica e fácies sedimentares do Espinhaço Setentrional e Chapada Diamantina (BA). In: Simpósio de Geologia de Minas Gerais, 5, Simpósio de Geologia de Brasília, I, Belo Horizonte, 1989. Anais... Belo Horizonte, SBG. P. $180-183$.

Uhlein A., Trompette R., Egydio-Silva M.1995. Rifteamentos superpostos e tectônica de inversão na borda sudeste do Cráton do São Francisco. Geonomos, 3:99-107.

Uhlein A., Trompette R. 1998. Os eventos geológicos do limite MesoproterozóicoNeoproterozóico nos Estados de Minas Gerais e Bahia. Revista da Escola de Minas, 51: 36-42.

Vance E.R., Harris J.W., Milledge H.J. 1973. Possible origins of a-damage in diamonds from kimberlite and alluvial sources. Mineral Magazine, 39:349360 .

White S.H., Boorder H., Smith C.B. 1995. Structural controls of kimberlite and lamproite emplacement. Journal of. Geochemical Exploration, 53:245-264.

Manuscrito A-1287

Recebido em 18 de novembro de 2001 Revisão dos autores em 28 de novembro de 2001 Revisão accita em 02 de dezembro de 2001 